\title{
ParB spreading requires DNA bridging
}

\author{
Thomas G.W. Graham, ${ }^{1,2,5}$ Xindan Wang, ${ }^{3,5}$ Dan Song, ${ }^{2,4}$ Candice M. Etson, ,2,4, \\ Antoine M. van Oijen, ${ }^{2,7}$ David Z. Rudner, ${ }^{3,8}$ and Joseph J. Loparo ${ }^{2,8}$ \\ ${ }^{1}$ Department of Systems Biology, Harvard Medical School, Boston, Massachusetts 02115, USA; ${ }^{2}$ Department of Biological \\ Chemistry and Molecular Pharmacology, Harvard Medical School, Boston, Massachusetts 02115, USA; ${ }^{3}$ Department of \\ Microbiology and Immunobiology, Harvard Medical School, Boston, Massachusetts 02115, USA; ${ }^{4}$ Harvard Biophysics \\ Program, Harvard Medical School, Boston, Massachusetts 02115, USA
}

The parABS system is a widely employed mechanism for plasmid partitioning and chromosome segregation in bacteria. ParB binds to parS sites on plasmids and chromosomes and associates with broad regions of adjacent DNA, a phenomenon known as spreading. Although essential for ParB function, the mechanism of spreading remains poorly understood. Using single-molecule approaches, we discovered that Bacillus subtilis ParB (Spo0J) is able to trap DNA loops. Point mutants in Spo0J that disrupt DNA bridging are defective in spreading and recruitment of structural maintenance of chromosomes (SMC) condensin complexes in vivo. DNA bridging helps to explain how a limited number of Spo0J molecules per parS site $(20)$ can spread over many kilobases and suggests a mechanism by which ParB proteins could facilitate the loading of SMC complexes. We show that DNA bridging is a property of diverse ParB homologs, suggesting broad evolutionary conservation.

[Keywords: ParB; Spo0J; single-molecule fluorescence; bacterial chromosome segregation]

Supplemental material is available for this article.

Received March 24, 2014; revised version accepted April 25, 2014.

Proper chromosome organization is essential for accurate DNA segregation in all organisms. In bacteria, nucleoidassociated protein complexes play a critical role in this process, yet the molecular mechanisms by which they facilitate chromosome segregation remain unclear (Wang et al. 2013). The parABS system promotes accurate chromosome segregation and plasmid partitioning across a wide range of bacterial species (Surtees and Funnell 2003). This partitioning module is composed of three components: a variant Walker-type ATPase called ParA, a DNA-binding protein called ParB, and a cis-acting DNA element called parS to which ParB binds with high affinity.

Plasmid ParB-parS complexes serve as centromere-like elements that ParA segregates by a mechanism that remains incompletely understood (Vecchiarelli et al. 2012). Chromosomal parABS systems likely function in a similar way, although instead of segregating entire chromosomes, they reposition the origin region where the parS sequences reside. In certain species, such as Caulobacter crescentus, the parA and parB genes are essential (Mohl et al. 2001), while in others, their loss-of-function phenotype is milder.

\footnotetext{
${ }^{5}$ These authors contributed equally to this work. Present addresses: ${ }^{6}$ Department of Chemistry, Tufts University, Medford, MA 02155, USA; ${ }^{7}$ Zernike Institute of Advanced Materials, University of Groningen, Groningen, 9700 AB, Netherlands ${ }^{8}$ Corresponding authors

E-mail joseph_loparo@hms.harvard.edu

E-mail david_rudner@hms.harvard.edu

Article published online ahead of print. Article and publication date are online at http://www.genesdev.org/cgi/doi/10.1101/gad.242206.114.
}

In Bacillus subtilis, deletion of the parB gene (called spo0I) results in a modest chromosome segregation defect $(\sim 1 \%$ anucleate cells), while deletion of parA (called soj) weakly affects origin positioning (Lee and Grossman 2006). Further complicating genetic analysis, chromosomal ParA and ParB have additional species-specific functions, including regulation of replication initiation, growth, and motility (Ireton et al. 1994; Bartosik et al. 2009; Scholefield et al. 2011).

Essential to the function of ParB proteins is their unusual ability to associate with nonspecific DNA adjacent to parS sites, a phenomenon called spreading. This property was inferred from the ability of overexpressed F plasmid SopB (ParB) to silence genes adjacent to sopC (parS) sites (Lynch and Wang 1995) and later directly demonstrated by chromatin immunoprecipitation (ChIP) experiments with ParB from P1 plasmid (Rodionov et al. 1999). A DNA-binding protein "roadblock" inserted on one side of the P1 plasmid parS site attenuated ParB spreading unidirectionally (Rodionov et al. 1999). Other plasmid ParB proteins, including KorB from plasmid RK2, can also exhibit spreading and reduce expression of neighboring genes (Bingle et al. 2005; Chiu et al. 2008).

\footnotetext{
(C) 2014 Graham et al. This article is distributed exclusively by Cold Spring Harbor Laboratory Press for the first six months after the full-issue publication date (see http://genesdev.cshlp.org/site/misc/terms.xhtml). After six months, it is available under a Creative Commons License (AttributionNonCommercial 4.0 International), as described at http://creativecommons. org/licenses/by-nc/4.0/.
} 
These observations led to the proposal that ParB nucleates on parS sites and polymerizes to form long filaments on DNA (Rodionov et al. 1999; Bingle et al. 2005; Murray et al. 2006).

Spreading is also a property of chromosomally encoded ParB proteins (Murray et al. 2006; Breier and Grossman 2007). There are typically several parS sites clustered near the origin of replication (Livny et al. 2007), and ParB is thought to form centromere-like complexes at these sites that are acted upon by ParA to promote segregation of the origin. In B. subtilis, ChIP-chip (ChIP coupled with microarray analysis) experiments have shown that ParB (Spo0J) associates with 10-20 kb of nonspecific DNA flanking each of its eight parS sites. Roadblock experiments with Spo0J suggest that the formation of onedimensional filaments is required for spreading, although Spo0J does not silence genes adjacent to parS sites (Murray et al. 2006; Breier and Grossman 2007). Fluorescent protein fusions to chromosomal ParBs form compact foci that colocalize with origins, suggesting that ParB may also gather the origin-proximal parS sites into a single complex (Glaser et al. 1997; Lin et al. 1997; Sullivan et al. 2009; Shebelut et al. 2010; Kusiak et al. 2011). In line with its proposed role as an organizer of the origin-proximal region, ParB is required to recruit the structural maintenance of chromosomes (SMC) condensin complex adjacent to the origin in B. subtilis and Streptococcus pneumoniae (Gruber and Errington 2009; Sullivan et al. 2009; Minnen et al. 2011). Bacterial SMC is thought to constrain the chromosome by bridging different segments of DNA (Hirano 2006). Spreading by ParB is necessary for SMC enrichment at parS sites, but the mechanism by which ParB recruits SMC is not known (Sullivan et al. 2009).

Here we used a combination of in vitro single-molecule experiments and in vivo imaging to investigate the molecular basis of spreading. We report a novel DNAbridging activity for $B$. subtilis SpoOJ and identify point mutants that are defective in both DNA bridging in vitro and spreading in vivo. Quantitative analysis of Spo0J stoichiometry at parS sites in vivo supports a role for long-range DNA bridging in complex assembly. Finally, the ability to bridge DNA is found to be conserved among chromosomal and plasmid-encoded ParB proteins from several different bacterial species. Our data are consistent with a model in which cooperative DNA bridging and nearest-neighbor interactions allow a modest number of ParB dimers $(\sim 20)$ to form a nucleoprotein complex spanning thousands of base pairs. The formation of long-distance DNA loops may help condense the originproximal region of the chromosome and facilitate SMC loading.

\section{Results}

\section{Spo0I cannot spread by filament formation alone}

It was previously proposed that ParB spreads by forming continuous nucleoprotein filaments that span thousands of base pairs (Rodionov et al. 1999; Bingle et al. 2005;
Murray et al. 2006). Given that Spo0J occupies 10-20 kb of DNA flanking each parS site and has a footprint of $~ 30$ base pairs (bp), this would imply that there are at least several hundreds of SpoOJ molecules per parS site (Murray et al. 2006). To determine the number of Spo0J molecules per cell, we performed quantitative immunoblots using anti-SpoOJ antibodies and purified SpoOJ protein as a standard (Fig. 1A). Our analysis revealed that there are $\sim 1400$ Spo0J molecules (700 dimers) per colony-forming unit (cfu). Because B. subtilis normally forms long chains, we used a strain that was engineered to express the cell separase LytF under inducible control (Chen et al. 2009). Under these conditions, the majority of cells were singlets and doublets with an average of 1.6 cells per cfu $(n=$ 1542) (Fig. 1B; Supplemental Table 1). To determine the number of origins per cell, we used a matched control strain that expressed TetR-CFP and harbored an array of tet $O$ operators adjacent to the origin (at $\left.-7^{\circ}\right)$ (Fig. 1B). Under the growth conditions used for the quantitative immunoblot, there were, on average, 3.1 origins per cell $(n=2530)$ (Supplemental Table 1). These results indicate that, on average, each cell contained 440 Spo0J dimers and 24 parS sites.

Assuming that all Spo0J dimers are in nucleoprotein complexes, this implies that $\sim 140$ Spo0J dimers are present at each origin. If these molecules are distributed among all eight origin-proximal parS sites, then nucleoprotein filament formation alone would allow for only $\sim 500$ bp of spreading per parS site, much less than the observed 10-20 kb (Murray et al. 2006; Breier and Grossman 2007). However, since ChIP is a population-based assay, it is possible that SpoOJ/parS complex formation is stochastic, and only one or two parS sites are occupied at each origin. To evaluate this possibility, we visualized foci of GFP-tagged Spo0J expressed from its native promoter in cells harboring all eight endogenous pars sites or in cells that contained four, two, or zero sites (Fig. 1C). As previously reported, GFP-Spo0J formed bright foci that colocalized with the origin region in exponentially growing cells (Fig. 1C; Lewis and Errington 1997; Lin et al. 1997; Sullivan et al. 2009). As parS sites were deleted, GFP-Spo0J foci at remaining parS loci separated into distinct spots. Double-labeling experiments in which we visualized GFP-Spo0J foci and an origin tag indicate that most if not all parS sites are occupied in all cells in these strains (Fig. 1C).

Together, these data indicate that in vegetatively growing B. subtilis cells, $\sim 20$ Spo0J dimers are associated with each parS site. These data are inconsistent with the model in which Spo0J spreads over vast stretches of nonspecific DNA by forming a continuous filament and suggest longer-range interactions between Spo0J molecules bound to DNA.

\section{Single-molecule experiments reveal a new DNA} bridging activity of SpoOJ

To investigate how Spo0J interacts with DNA, we turned to single-molecule imaging. Individual 48.5 -kb-long molecules of bacteriophage $\lambda$ genomic DNA were tethered at 


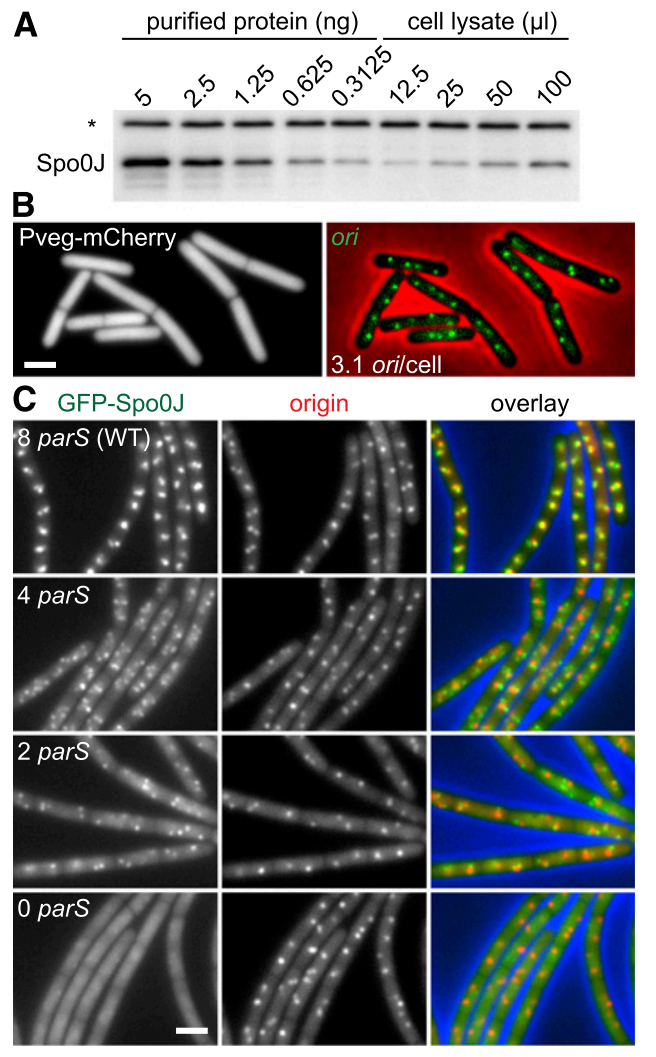

Figure 1. Measurement of the number of Spo0J dimers per parS site. (A) Quantitative immunoblot to determine the intracellular concentration of Spo0J. Serial dilutions of a B. subtilis lysate and purified Spo0J were separated by SDS-PAGE and probed with anti-SpoOJ antiserum. Samples were diluted with a $\Delta$ spoOJ lysate such that all lanes had the same amount of whole-cell lysate (see the Materials and Methods). A cross-reacting protein in the lysate (asterisk) served as a loading control. To accurately assess the number of colony-forming units (cfus) in the culture used to generate the lysate, the strain expressed the cell separase LytF. Under these conditions, cells were predominantly singlets and doublets (see Supplemental Table 1) rather than septated chains. (B) Analysis of number of origins per cell. Representative micrograph of matched control cells grown under the same conditions used for the quantitative immunoblot. In addition to expressing the cell separase LytF, these cells expressed cytoplasmic mCherry (grayscale) to define cell outlines and contained an origin-proximal tetO48 array labeled with TetR-CFP (green) for counting origins (see Supplemental Table 1). (C) Localization of GFP-Spo0J and replication origins in strains containing eight (wild-type), four, two, or zero parS sites. (Left panel) GFP-Spo0J. (Middle panel) Replication origins marked with tetO48 and TetR-mCherry. (Right panel) Overlay of GFP-Spo0J (green), origins (red), and phase contrast (blue). Fluorescence intensity for each channel was adjusted to the same scale for all strains. Bar, $2 \mu \mathrm{m}$.

one end to a functionalized glass coverslip, extended by buffer flow through a microfluidic flow cell, and imaged by total internal reflection fluorescence (TIRF) microscopy in the presence of the intercalating dye SYTOX Orange. Strikingly, flowing purified SpoOJ protein into the flow cell caused displacement of the SYTOX dye and compaction of $\lambda$ DNA into a tight focus (Fig. 2A). DNA compaction occurred rapidly at modest protein concentrations $(\leq 100 \mathrm{nM})$ and could be reversed by washing with buffer (Supplemental Fig. 1a,b). Similar results were obtained for $\lambda$ DNA engineered with a single internal parS site (Fig. 2E), indicating that the interactions that we studied in this assay are not strictly parS-dependent. Similar parS-independent association of ParB/Spo0J with DNA had been observed in previous in vitro studies and likely reflects the fact that ParB proteins must engage in extensive interactions with nonspecific DNA in order to spread in vivo (Murray et al. 2006; Havey et al. 2012).

To resolve DNA motions in more detail, we labeled the five EcoRI sites in $\lambda$ DNA using quantum dots (QDs) conjugated to catalytically inactive EcoRI ${ }^{\mathrm{E} 111 \mathrm{Q}}$ (Wright et al. 1989; Finkelstein et al. 2010). Because this approach allows us to track specific positions on a moving strand of DNA, we called it "DNA motion capture" by analogy to motion capture techniques used in computer animation. DNA motion capture revealed that DNA compaction by Spo0J was dramatically biased toward the free end of DNA, with QDs close to the end moving toward the tether first (Fig. 2C; Supplemental Movie 1). Similar end-biased compaction was also observed for the known Escherichia coli DNA-bridging protein H-NS (Supplemental Fig. 1f). In contrast, HBsu, the B. subtilis homolog of the well-studied E. coli nucleoid protein HU (van Noort et al. 2004), caused compaction uniformly along the DNA molecule (Fig. 2D; Supplemental Movie 2). In accord with previous singlemolecule studies, appropriate buffer conditions and protein concentrations caused extension of the DNA molecule, consistent with a second filamentous mode of HBsu and H-NS binding (Supplemental Fig. 1c,g; van Noort et al. 2004; Liu et al. 2010).

The distinct behaviors of SpoOJ, H-NS, and HBsu can be explained by a simple physical model: The tension at any point along a flow-stretched piece of DNA is approximately equal to the net drag force on DNA beyond that point. Thus, tension will be highest at the tether and will drop to zero at the free end. HU proteins condense DNA by introducing flexible local bends, each of which causes only a small change in the end-to-end length of DNA (Swinger and Rice 2004). As a result, condensation of DNA by $B$. subtilis HBsu is not predicted to be strongly suppressed by the $<1 \mathrm{pN}$ forces exerted on DNA in our assay, and compaction by HBsu therefore occurs along the entire DNA molecule (Xiao et al. 2010, 2011; Wagner et al. 2011; TGW Graham and JJ Loparo, unpubl.). In contrast, the end bias in compaction by SpoOJ and H-NS suggests that each compaction step involves trapping a much larger loop of DNA. Such loops will form preferentially at the free end of the flow-stretched DNA, where the drag force is lowest, while loop formation will be strongly suppressed by even subpiconewton forces in the interior of the molecule, leading to endbiased compaction (Blumberg et al. 2005; Sankararaman and Marko 2005; Skoko et al. 2005, 2009). Consistent with this model, the end bias of compaction by Spo0J was substantially reduced by precoating the DNA with HBsu, which is expected to lower the energetic barrier to loop 


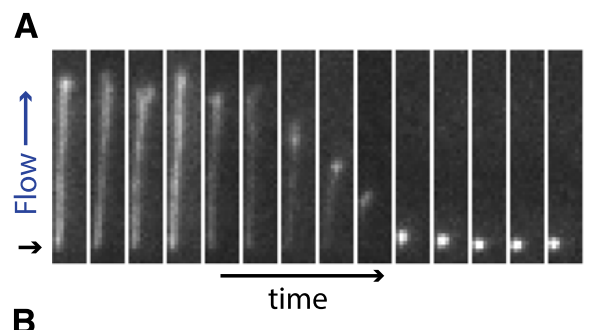

A

B

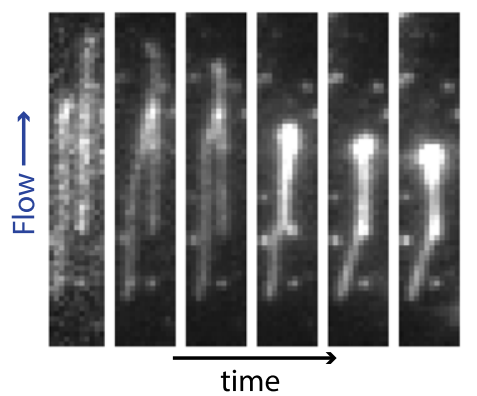

D
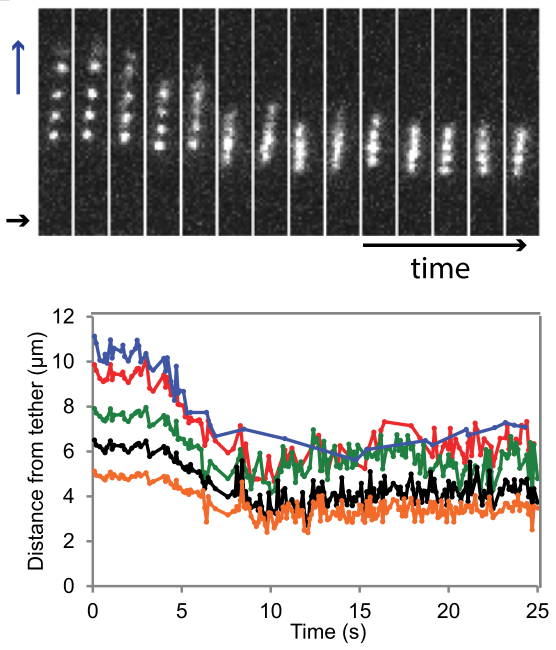

C
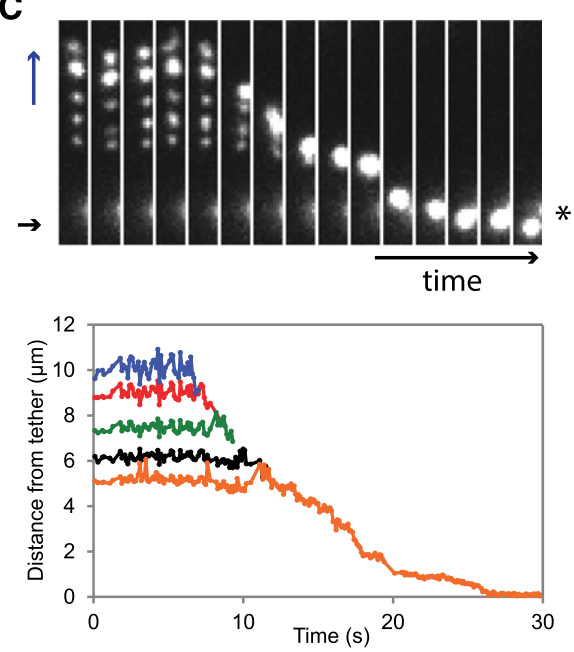

$\mathbf{E}$
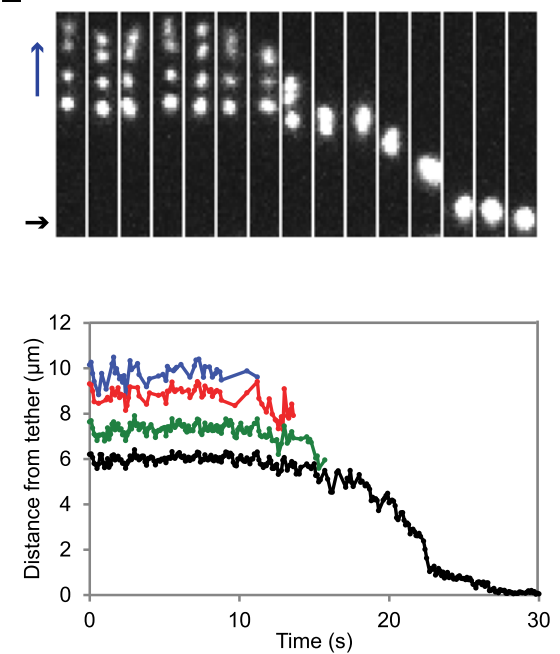

Figure 2. SpoOJ and HBsu compact flow-stretched DNA by different mechanisms. (A) Montage showing compaction of SYTOX Orange-stained $\lambda$ DNA by $100 \mathrm{nM}$ Spo0J protein (1.1 sec/frame). Binding of protein leads to partial displacement of the intercalating dye followed by compaction of DNA into a tight focus at the tether point (indicated by the small black arrow on the left). $(B)$ Crosslinking of adjacent DNAs by Cy3-labeled Spo0J. DNAs coated by Spo0J-Cy3 stick together upon collision and are "zipped up" by the DNA-bridging activity of Spo0J (15 sec/frame). $(C, D) \lambda$ DNA was labeled at EcoRI sites with EcoRI ${ }^{\mathrm{E} 111 \mathrm{Q}}$-conjugated QDs, extended by buffer flow, and exposed to $100 \mathrm{nM}$ Spo0J protein $(C)$ or $144 \mathrm{nM} \mathrm{HBsu}$ protein $(D)$. Montages of frames from compaction movies ( $2 \mathrm{sec} /$ frame) are shown in the top panels, while tracking of individual QDs by Gaussian fitting is shown in the bottom panels. Compaction of flow-stretched DNA by Spo0J occurred from the free end of the molecule and proceeded to the tether point, while compaction by HBsu occurred along the length of the molecule and did not proceed to the tether point. The asterisk in $C$ indicates a QD that is nonspecifically bound to the surface at the edge of the field of view. (E) Compaction of of $\lambda^{\text {pars }}$ DNA by $100 \mathrm{nM}$ Spo0J protein ( $2 \mathrm{sec} /$ frame). Note that the EcoRI site closest to the tether is deleted in $\lambda^{\text {pars }}$ by insertion of the cassette containing parS, leaving four labeled EcoRI sites.

formation in the interior of the DNA molecule (Supplemental Fig. 1d,e; Becker et al. 2007).

To directly observe Spo0J binding to DNA, we introduced a three-amino-acid tag containing a unique cysteine at the $\mathrm{C}$ terminus of SpoOJ and fluorescently labeled it with Cy3-maleimide (Garner et al. 2007). Introduction of the same tag at the $\mathrm{C}$ terminus of Spo0J in vivo had no effect on the formation of either GFP-Spo0J foci or SMC complexes (Supplemental Fig. 2g,h). Simultaneous imag- ing of Spo0J-Cy3 and spectrally distinct EcoRI ${ }^{\mathrm{E} 111 \mathrm{Q}}-\mathrm{QD}$ revealed that Spo0J-Cy3 bound nonspecifically along $\lambda$ DNA and caused end-biased compaction in the same manner as unlabeled Spo0J. We could detect no specific enrichment of Cy3-labeled Spo0J near the parS site on $\lambda^{\text {pars }}$ DNA (data not shown), which is consistent with the rapid nonspecific binding of Spo0J to DNA and parSindependent DNA compaction observed under these conditions (Fig. 2E). In support of the idea that SpoOJ can bridge 
segments of DNA, adjacent $\lambda$ DNAs bound by SpoOJ-Cy3 often stuck together when they collided (Fig. 2B). Bridging of adjacent SYTOX- or QD-labeled DNAs was also seen with unlabeled SpoOJ. Similar to other DNA-binding proteins that have been examined in single-molecule experiments, Spo0J dimers were seen to diffuse one-dimensionally along DNA at very low $(<1 \mathrm{nM})$ concentrations (Supplemental Fig. 2a-f).

It appeared that compaction began only after a sufficient amount of fluorescently labeled protein had accumulated on the DNA. To study this more quantitatively, we imaged SpoOJ-Cy3 binding to $\lambda$ DNA with a single spectrally distinct $\mathrm{QD}$ at the free end to clearly define the start of compaction. The relative amount of SpoOJ bound to DNA over time was measured by summing the fluorescence intensity along each DNA in the Cy3 channel (Fig. 3A). Binding of Spo0J to DNA coincided with its arrival in the flow cell, as measured by the increase in background fluorescence. Compaction began significantly after the arrival of SpoOJ but before binding had reached saturation (Figs. 3A, 5C [below]). To measure the lag time between SpoOJ arrival and DNA compaction, we used unlabeled SpoOJ mixed with a small amount of tracer dye to indicate when the protein reached the flow cell. The lag time between protein arrival and the start of compaction decreased significantly with increasing protein concentration (Fig. 3B). These data are consistent with the idea that SpoOJ first binds nonspecifically to flow-stretched DNA and induces compaction when DNA-bound proteins are brought together by random collisions between DNA segments. In contrast, HBsu initiated DNA compaction almost immediately upon arrival of the protein, with the slight delay likely reflecting the finite mixing time within the flow cell (Fig. 3B). As expected for an elementary compaction step that involves a single HBsu dimer binding and distorting DNA, the rate of compaction by HBsu varied linearly with the protein concentration (Fig. 3D). However, the rate of compaction by Spo0J scaled approximately with the square of the protein concentration, consistent with a model in which protein-protein interactions on opposite sides of a DNA loop are required for each compaction step (Fig. 3C).

Collectively, these single-molecule results reveal a new DNA-bridging activity of SpoOJ that allows it to trap loops between distal segments of DNA. DNA looping could explain how a mere $\sim 20$ SpoOJ dimers per parS site can occupy $10-20 \mathrm{~kb}$ of adjacent DNA in vivo.

\section{Bridging-deficient mutants fail to spread in vivo}

If DNA bridging is required for spreading of SpoOJ in vivo, then SpoOJ mutants that are impaired in DNA bridging in our single-molecule assay should also fail to spread in vivo. To test this prediction, we examined various mutants identified from earlier screens and also introduced mutations in other highly conserved residues (see Supplemental Table 2). As a proxy for in vivo spreading, we used the ability of GFP-tagged Spo0J to form fluorescent foci in cells (Breier and Grossman 2007). We generated a new fusion protein with the GFP variant mGFPmut3, which has recently been shown to have a lower propensity to aggregate nonspecifically than other fluorescent proteins (Landgraf et al. 2012). mGFPmut3-Spo0J was expressed in a spo0J deletion strain under the control of its native promoter. Consistent with previous reports that dimerization is important for specific and nonspecific interactions with DNA (Leonard et al. 2004; Murray et al. 2006), truncation of the C-terminal dimerization domain by 20 or 60 amino acids eliminated fluorescent foci in vivo and abolished DNA binding and compaction in vitro (Fig. 4C; data not shown). Previous genetic screens identified the Spo0J lossof-function mutants G77S and R80A within the highly conserved N-terminal ParB Box II (Fig. 4A). Consistent with reported results, we found that GFP fusions to these mutants were impaired in focus formation (Fig. 4C; Supplemental Fig. 3; Autret et al. 2001; Breier and Grossman 2007). GFP-Spo0 ${ }^{\mathrm{R} 80 \mathrm{~A}}$ localization was diffuse and nucleoid-associated, while GFP-Spo0J ${ }^{\mathrm{G} 77 \mathrm{~S}}$ showed mostly diffuse localization with occasional faint foci. Substitution of the adjacent highly conserved R79 residue to alanine resulted in diffuse nucleoid-associated localization, while mutation of R82 to alanine reduced the intensity of GFPSpoOJ foci and increased diffuse localization. Mutation of R80 to lysine partially restored focus formation compared with R80A, suggesting that the positive charge of this residue is important for complex formation. Combining the partial loss-of-foci mutations R80K and R82A led to a complete loss of foci (Fig. 4C; Supplemental Fig. 3). Immunoblot analysis revealed that all of our GFP-Spo0J mutants were full length and accumulated to levels similar to wild type (Fig. 4B).

Using ChIP combined with deep sequencing (ChIP-seq), we investigated whether the R79A and R80A mutants associate with parS and spread on adjacent DNA. As observed in previous ChIP-chip experiments, wild-type Spo0J was highly enriched at all eight origin-proximal parS sites and spread for 5-10 kb on either side of each parS site, while G77S associated with parS sites but failed to spread to adjacent DNA (Fig. 4D). Consistent with their inability to form foci, the R79A and R80A mutants also failed to spread despite associating with parS sites (Fig. 4D). Together with in vitro binding assays (see below), these results indicate that these mutant proteins have retained their ability to bind parS DNA and are specifically defective in spreading.

We also tested these nonspreading mutants in our singlemolecule DNA-bridging assay. Spo0J R79A and R80A mutant proteins failed to compact DNA under buffer conditions that result in rapid compaction by wild-type Spo0J (Fig. 5A). These two mutants likewise failed to compact DNA in a reduced-salt buffer (Supplemental Fig. 4a). Consistent with its intermediate loss-of-foci phenotype in cells, R82A failed to compact DNA in our standard compaction buffer (Fig. 5A) but compacted DNA at a reduced salt concentration (Supplemental Fig. 4a). Importantly, electrophoretic mobility shift assays (EMSA) revealed that R79A, R80A, and R82A bound short parS DNA duplexes in a manner indistinguishable from wild type (Fig. 5D). To determine whether the R80A mutant accumulates to the same level as wild-type Spo0J on $\lambda$ DNA, we calibrated the intensity of Cy3-labeled protein 
A

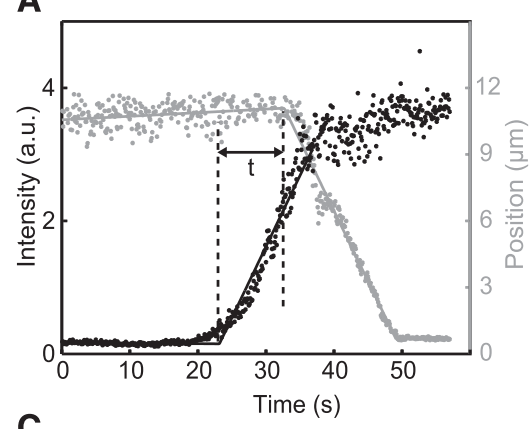

C

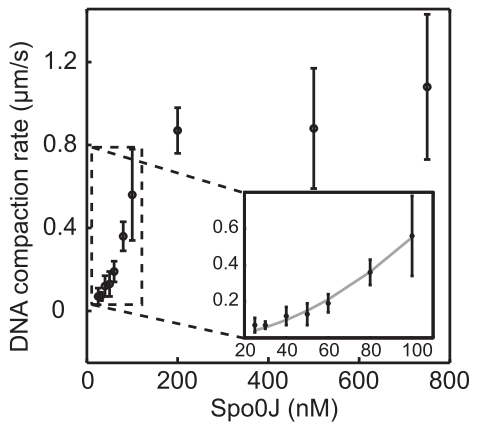

B

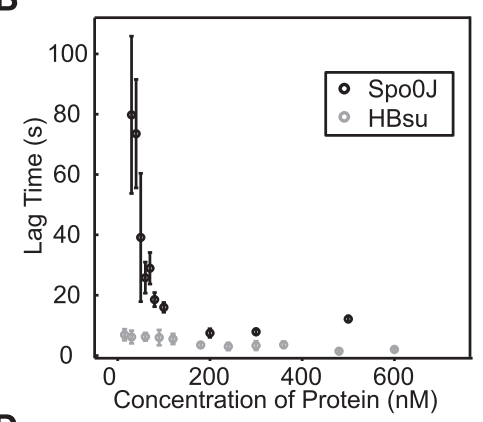

D

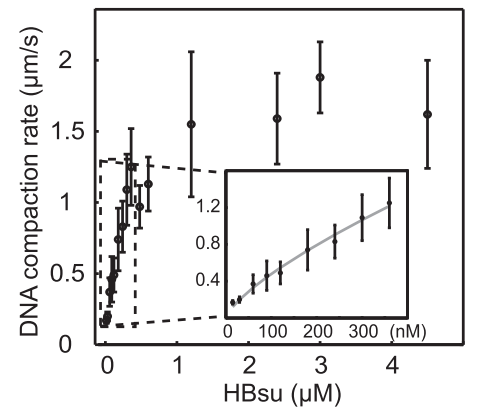

Figure 3. Dependence of compaction rate and lag time on Spo0J protein concentration. DNA substrates were end-labeled with a QD, and the position of the end of the DNA molecule was monitored over time by particle tracking. $(A)$ Integrated intensity of bound Cy3-Spo0J over time (black) and position of the end label (gray), showing a lag time $(t)$ between initial binding of the protein and the onset of compaction. (B) Influence of protein concentration on the lag time between arrival of unlabeled protein (indicated by the appearance of a fluorescent tracer dye) and initiation of compaction. Compaction by Spo0J shows a substantial concentration-dependent lag time, while the delay in compaction by HBsu is essentially diffusionlimited. Shown are means \pm standard deviation. $(C, D)$ Compaction rate as a function of protein concentration for Spo0J $(C)$ and HBsu $(D)$, showing an initial nonlinear dependence of compaction rate on protein concentration for the former and an initial linear dependence for the latter. Shown are means \pm standard deviation. The insets show a power law fit (gray line) to the initial data points. Best-fit exponents were $1.88(C)$ and $0.73(D)$, with $R^{2}$ values of 0.988 and 0.987 , respectively. on DNA to that of individual Cy3 molecules to estimate the absolute density of proteins bound to DNA (see the Materials and Methods). Based on our measurements, compaction by wild-type Spo0J initiated at a protein density of 10 plus or minus two dimers per kilobase of DNA (Fig. 5C, gray dashed line). Cy3-labeled SpoOJ ${ }^{\mathrm{R} 80 \mathrm{~A}}$ associated with $\lambda$ DNA with identical kinetics and reached a similar final density (Fig. 5C) yet failed to compact $\lambda$ DNA or cross-link adjacent DNA molecules (Fig. 5B; Supplemental Movie 3). Together with the phenotypes of the R79A, R80A, and R82A mutants in vivo, these results support the model in which SpoOJ spreading requires DNA bridging and implicate an "arginine patch" in the ParB Box II that is essential for bridging interactions.

Interestingly, the spreading-deficient G77S mutant compacted $\lambda$ DNA and bridged adjacent DNAs (Fig. 5A; data not shown). In fact, G77S compacted DNA at a higher salt concentration than the wild-type protein (Supplemental Fig. 4a). Likewise, the R149A mutant was impaired in complex formation in vivo yet showed only a mild defect in DNA compaction in vitro (Fig. 5A; Supplemental Fig. 4a). These results imply that the DNA-bridging activity of Spo0J, while necessary for spreading, is not sufficient. The fact that G77S and R149A are unimpaired (or only mildly impaired) in loop formation suggests that they are defective in some other step in the spreading process. In EMSA experiments with a short parS-containing DNA duplex, G77S and R149A produced an anomalous pattern of shifted complexes compared with wild-type Spo0J (Fig. 5E; Supplemental Fig. 4e), a result that was previously observed for G77S (Breier and Grossman 2007). This suggests that defective spreading by G77S and R149A in vivo may result from a defect in parS-dependent interactions that were not probed by our single-molecule assay (see the Discussion). The fact that G77S is proficient (and perhaps even hyperactive) in DNA bridging might also explain the occurrence of weak residual GFP-Spo0J ${ }^{\mathrm{G} 77 \mathrm{~S}}$ foci (Fig. 4C; Supplemental Fig. 3) and an elevated ChIP signal at parS sites compared with the bridging-deficient R79A and R80A mutants (Fig. 4D).

DNA bridging-deficient mutants of SpoOJ exhibit abnormal nucleoid morphology and fail to recruit the SMC complex

We investigated whether Spo0J mutants that are impaired in DNA bridging in vitro are defective in chromosome morphology and SMC enrichment (Ireton et al. 1994; Lee and Grossman 2006; Gruber and Errington 2009; Sullivan et al. 2009). We grew cells harboring wild-type or mutant spoOJ in rich medium and imaged the nucleoids using DAPI (4',6-diamidino-2-phenylindole) or an mCherryHBsu fusion. More than 500 nucleoids for each strain were analyzed quantitatively. Similar to the null mutant, cells harboring bridging-deficient Spo0J mutants had elongated nucleoids (Supplemental Fig. 5). To investigate the impact of these mutants on condensin complexes, we used a YFP fusion to the SMC accessory subunit ScpB. In wild-type cells, ScpB-YFP (and GFP-SMC) forms fluorescent foci that colocalize with the origin of replication (Gruber and Errington 2009; Sullivan et al. 2009). Consistent with previous findings, ScpB-YFP localization was significantly reduced in cells lacking SpoOJ and in cells expressing the bridging-deficient SpoOJ ${ }^{\mathrm{R} 79 \mathrm{~A}}$ and Spo0J ${ }^{\mathrm{R} 80 \mathrm{~A}}$ mutants (Fig. 6A). Importantly, the loss of localization was not a consequence of ScpB-YFP proteolysis, as ScpBYFP remained intact in all mutants analyzed (Fig. 6B). Furthermore, the levels of Spo0J mutant proteins were all similar to wild type. Thus, bridging-deficient Spo0J mutants have abnormal nucleoid morphologies and are 
A
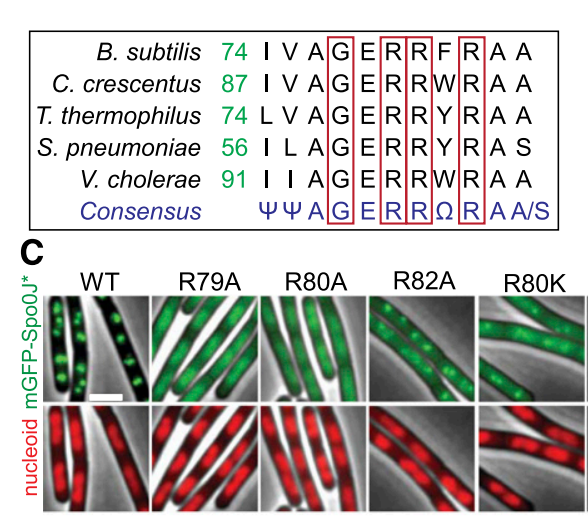

D

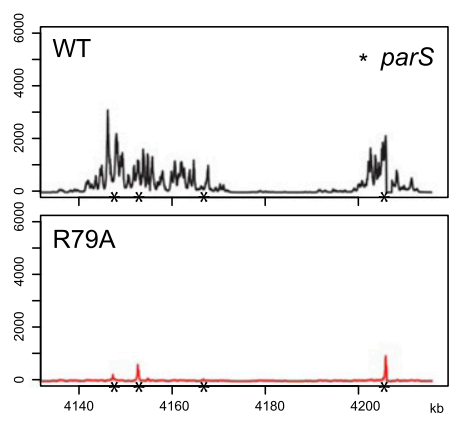

B
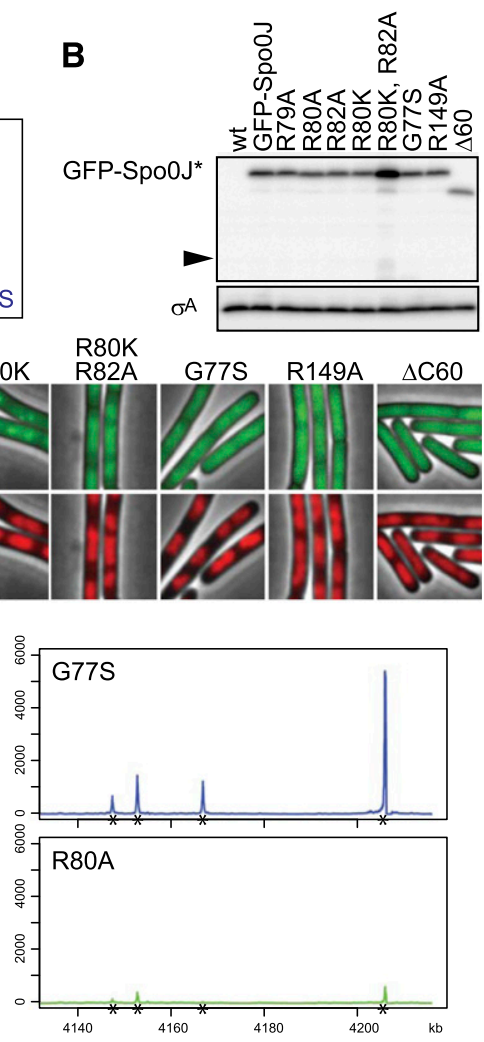

Figure 4. In vivo characterization of Spo0J spreading-deficient mutants. (A) Alignment of the ParB Box II of different species showing key mutated residues (red boxes). (B) Western blot of mGFPmut3-tagged Spo0J variants. All fusion proteins are intact and are expressed at comparable levels (except for the double mutant). The size of free GFP is indicated (arrowhead). $\sigma^{\text {A }}$ levels are shown to control for loading. (C) Localization of fluorescently tagged Spo0J variants (green). The nucleoid is labeled with HBsu-mCherry (red), and phase-contrast images are shown in gray. Bar, $2 \mu \mathrm{m}$. (D) ChIP-seq of wild-type and mutant SpoOJ association with a region of the $B$. subtilis chromosome from $354^{\circ}$ to $359^{\circ}$ (4140-4215 $\mathrm{kb}$ ) encompassing four parS sites (asterisks). Fold enrichment (Y-axis) was normalized to input DNA and total number of reads per sample (see the Materials and Methods). Whereas wild-type Spo0J spreads several kilobases from parS sites, association of the G77S, R79A, and R80A mutants is restricted to the immediate vicinity of each pars site.

impaired in the recruitment of SMC complexes to the replication origin.

\section{ParB homologs are capable of DNA bridging}

Given the high degree of conservation among parABS systems, we asked whether the ability to trap DNA loops is a conserved feature of ParB proteins. Consistent with previous reports of pairing of plasmids by $\mathrm{P} 1$ plasmid ParB in vivo and formation of large cross-linked complexes between P1 ParA, ParB, and DNA in solution (Edgar et al. 2001; Havey et al. 2012), we found that P1 ParB compacted and bridged DNA in single-molecule experiments (Fig. 6C). Other chromosomally encoded ParBs from S. pneumoniae, Pseudomonas aeruginosa, and chromosome 1 of Vibrio cholerae behaved similarly (Fig. 6C). Thus, DNA bridging is likely to be a broadly conserved property of ParB proteins.

\section{Discussion}

\section{DNA bridging is required for SpoOI spreading}

ParB proteins, including B. subtilis Spo0J, have a remarkable ability to "spread" from high-affinity parS sites to adjacent nonspecific DNA. However, the molecular basis of spreading has remained unclear. Previous studies have concluded that ParB proteins form continuous onedimensional filaments along DNA (Rodionov et al. 1999; Murray et al. 2006; Breier and Grossman 2007; Sullivan et al. 2009), yet a filament-only model is inconsistent with our quantitative immunoblots, which indicate that $\sim 20$ Spo0J dimers are associated with each parS site. Based on our single-molecule experiments, we propose an alternative mechanism in which long-range DNA-bridging interactions cooperate with short-range nearest-neighbor interactions to assemble Spo0J complexes spanning many kilobases of DNA (Fig. 7). Such a model accounts for both long-distance spreading and the ability of protein roadblocks to bias spreading unidirectionally by impeding local nearest-neighbor interactions (Broedersz et al. 2014). In contrast to a filament-only model, which would predict repression of genes coated by a Spo0J filament, the bridging model also explains why genes within regions of Spo0J spreading are not silenced (Breier and Grossman 2007). Combining long-distance DNA-bridging interactions (Fig. 7B) with short-distance nearest-neighbor interactions (Fig. 7C) would result in a highly cooperative assembly of nucleoprotein complexes (Fig. 7D). Formation of short filaments could stabilize loops through an avidity effect and enable interactions between multiple loops (Fig. 7E). Our observation that ParB homologs from various species can also bridge DNA (Fig. 6C) suggests that this mechanism of spreading is evolutionarily conserved.

In support of the role of DNA bridging in Spo0J spreading, we identified a patch of arginine residues in the ParB Box II that are essential for both DNA loop formation in vitro and Spo0J complex formation in vivo. These adjacent residues could form a positively charged 
A

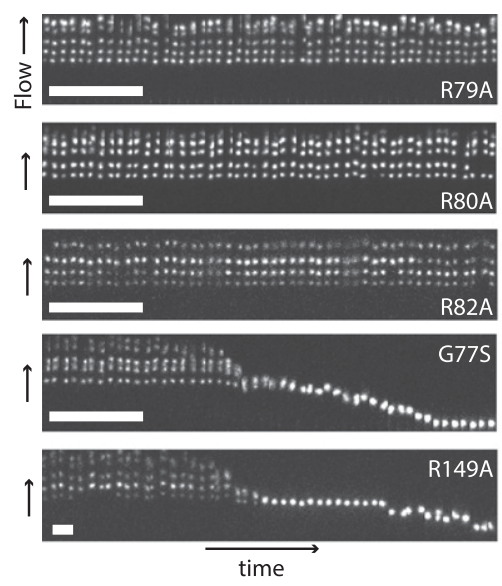

D

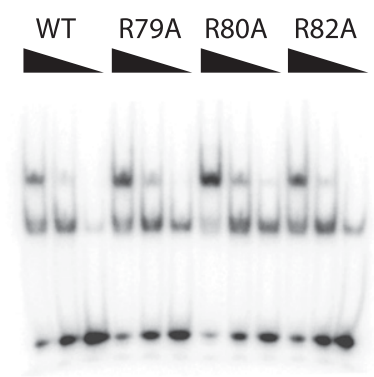

B

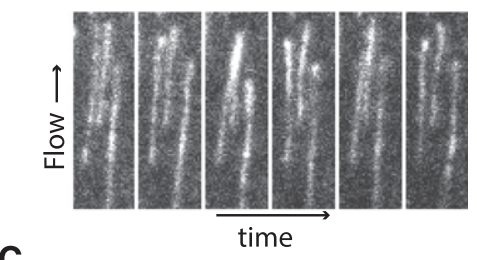

C

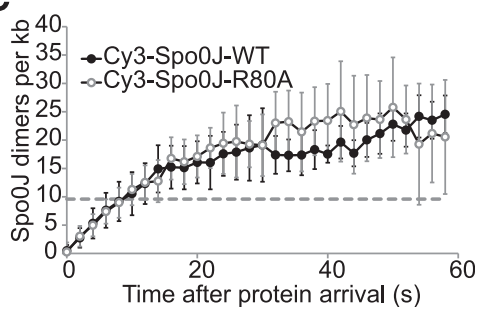

E

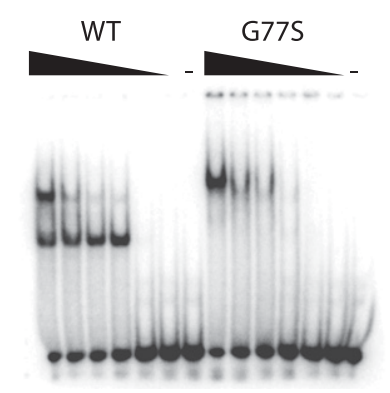

Figure 5. In vitro characterization of SpoOJ nonspreading mutants. (A) $\lambda$ DNA compaction by different purified SpoOJ mutant proteins in buffer containing $100 \mathrm{mM} \mathrm{NaCl}$. Bar, 5 sec. (B) Cy3-Spo0J ${ }^{\mathrm{R} 80 \mathrm{~A}}$ binds to DNA without inducing compaction or cross-linking. (1.5 sec/frame). (C) Absolute density of Cy3-labeled wild-type SpoOJ and SpoOJ ${ }^{\mathrm{R} 80 \mathrm{~A}}$ bound to $\lambda$ DNA over time expressed as number of dimers per kilobase. Labeled protein was combined with unlabeled protein and diluted such that the total protein concentration was $100 \mathrm{nM}$, and $5 \%$ of the protein was labeled. Under these conditions, compaction by wild-type Spo0J initiated at $\sim 10$ plus or minus two dimers per kilobase (dashed gray line). $(D, E)$ EMSA of wild-type and mutant SpoOJ proteins. Protein concentrations were $1,0.5$, and $0.2 \mu \mathrm{M}$ for $D$ and $1,0.8,0.6,0.4,0.2,0.1$, and $0 \mu \mathrm{M}$ for $E$. surface that interacts with a negatively charged region on another Spo0J molecule or with the backbone of another segment of DNA. We favor the former explanation because the nonlinear scaling of the DNA compaction rate with Spo0J concentration is consistent with dimerdimer interactions. Negatively charged residues that form salt bridges with the ParB Box II arginines in the crystal structure of Thermus thermophilus Spo0J are not conserved in B. subtilis Spo0J, and mutation of nearby negatively charged residues had no effect on focus formation in vivo and compaction in vitro (data not shown), and so the location of the putative ParB Box II-interacting surface remains to be determined.

Consistent with the idea that bridging interactions are necessary but not sufficient for Spo0J spreading, some mutants with defects in spreading or focus formation in vivo nonetheless compacted DNA in single-molecule experiments (Fig. 5A; Supplemental Table 2). We hypothesize that these spreading-deficient but bridging-proficient mutants are impaired in nearest-neighbor interactions or some other parS-dependent interaction that was not probed by our assay. Two mutants in this class, G77S and R149A, showed unusual behavior in EMSAs compared with wild-type Spo0J, suggesting that they adopt an abnormal conformation when bound to parS (Fig. 5E; Supplemental Fig. 4e; Breier and Grossman 2007). Consistent with this interpretation, the Spo0J crystal structure from T. thermophilus places G77 at the crux of a sharp turn, with dihedral angles that suggest that replacement with serine would cause a large structural distortion in the protein. R149 is located in a predicted helix-turn-helix domain of the protein that is thought to make sequencespecific contacts with DNA, consistent with the idea that mutation of this residue distorts the parS-bound conformation of the protein. Determining the structure of Spo0J bound to parS and identifying how the G77S and R149A mutants distort this structure will be important areas for future work.

\section{Implications for chromosome structure and segregation}

The ability of Spo0J to trap DNA loops has important implications for how it might organize the origin region of the chromosome. Our results indicate that the extensive spreading of Spo0J from parS is accomplished by a modest number of dimers ( $\sim 20$ per parS site) that are capable of trapping DNA loops (Fig. 7E). These loops could help to constrain the origin region and participate in defining topological domains in the same way that the E. coli $\mathrm{H}-\mathrm{NS}$ and MatP proteins are thought to organize H-NS-regulated operons and chromosome termini, respectively (Wang et al. 2011; Dupaigne et al. 2012). Furthermore, our finding that reducing the number of parS sites in vivo leads to a loss of ParB/parS clustering (Fig. 1C) suggests that specific parS sites or the number or positions of these sites play an important role in generating a larger chromosomal domain.

ParB proteins are critical for enriching SMC complexes near the origin in B. subtilis and $S$. pneumoniae, yet it is unclear how they accomplish this (Gruber and Errington 2009; Sullivan et al. 2009; Minnen et al. 2011). Previous 
A

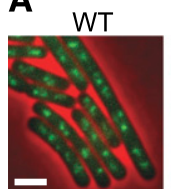

R79A
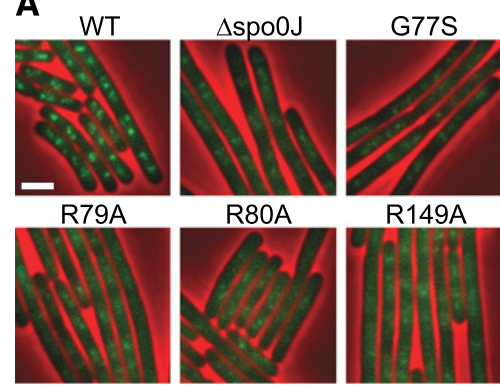

R149A

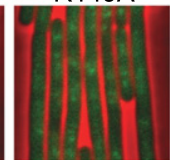

B

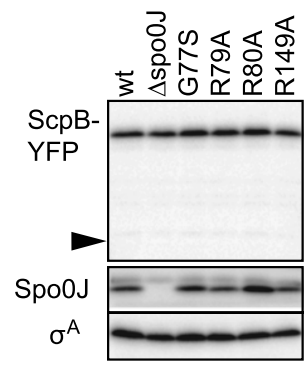

C

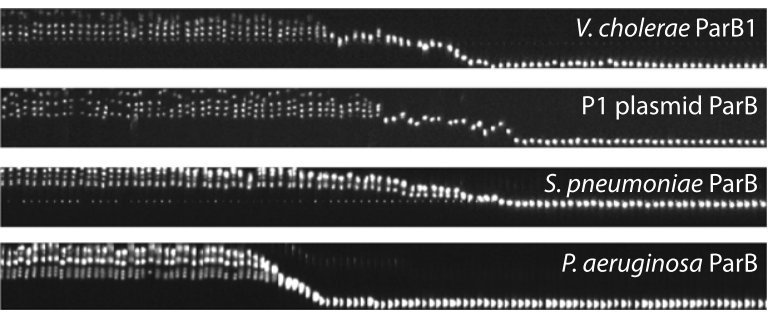

Figure 6. SMC complex localization is disrupted by nonspreading mutants of SpoOJ. (A) ScpB-YFP localization in wild-type (WT) and SpoOJ mutants. (Green) YFP; (red) phase contrast. The fluorescence signal in different images is adjusted to the same scale. Bar, $2 \mu \mathrm{m}$. (B) Western blots (with $\sigma^{\mathrm{A}}$ as a loading control) showing comparable levels of ScpB-YFP and SpoOJ in the different strains imaged in $A$. The size of free GFP is indicated (arrowhead). (C) Compaction of flow-stretched EcoRI-QD-labeled DNA by ParB homologs from different bacterial species. Protein concentrations were $100 \mathrm{nM}$ (P1, S. pneumoniae, and P. aeruginosa ParB) and $140 \mathrm{nM}$ (V. cholerae ParB1). Time per frame was $250 \mathrm{msec}$ for $\mathrm{P} 1,2 \mathrm{sec}$ for $V$. cholerae, $1.1 \mathrm{sec}$ for $S$. pneumoniae, and $110 \mathrm{msec}$ for $P$. aeruginosa.

work demonstrated that SMC can be chemically crosslinked to Spo0J in vivo, suggesting a direct physical interaction between the two proteins /Gruber and Errington 2009). Given that SMC complexes are also proposed to bridge DNA, our model of Spo0J complex formation suggests a mechanism by which SpoOJ could facilitate SMC loading by recruiting SMC to trapped DNA loops (Fig. 7E).

\section{Materials and methods}

Protein purification

Wild-type and mutant SpoOJ proteins, ParB homologs, HBsu, $\mathrm{H}-\mathrm{NS}$, and H6-EcoRI ${ }^{\mathrm{E} 111 \mathrm{Q}}$ were expressed and purified as described in the Supplemental Material.

\section{DNA compaction and SpoOI sliding experiments}

Details of flow cell construction and single-molecule imaging are described in the Supplemental Material. Bacteriophage $\lambda$ genomic DNA (New England Biolabs) was biotinylated on one end by annealing and ligating phosphorylated oligonucleotide BL1 (Supplemental Material) to one cos site overhang. Carboxyl-coated 605-nm QDs (Life Technologies) were conjugated to mouse antiHis6 antibody (AbD Serotec, MCA1396) following the manufacturer's instructions. Bacteriophage $\lambda$ genomic DNA (70 pM) was preincubated for at least $30 \mathrm{~min}$ at room temperature in EcoRI- binding buffer $(20 \mathrm{mM}$ Tris at $\mathrm{pH} 7.5,150 \mathrm{mM} \mathrm{KCl}, 100 \mu \mathrm{g} / \mathrm{mL}$ BSA) with $50 \mathrm{nM}$ anti-His6 QDs and $50 \mathrm{nM}$ (dimer concentration) His6-EcoRI ${ }^{\mathrm{E} 111 \mathrm{Q}}$ in a $20-\mu \mathrm{L}$ reaction volume. The volume of the mixture was then increased with $1 \mathrm{~mL}$ of additional EcoRIbinding buffer. The coverslip surface of 2-mm-wide flow cells was coated with streptavidin, washed, and incubated with preincubated EcoRI ${ }^{\mathrm{E} 111}$-QD-labeled $\lambda$ DNA for $\sim 10 \mathrm{~min}$ or until a suitable density of tethered DNAs was seen. Flow cells were washed with reaction buffer $(20 \mathrm{mM}$ Tris at $\mathrm{pH} 7.5,100 \mu \mathrm{g} / \mathrm{mL}$ BSA, the indicated concentrations of $\mathrm{NaCl}$ ), and protein in the same buffer was introduced into the flow cell at a flow rate of 50 $\mu \mathrm{L} / \mathrm{min}$. For salt dependence experiments, $100 \mathrm{nM}$ protein was introduced in buffers of decreasing salt concentration for $3 \mathrm{~min}$ each with 30-sec pauses in between steps. For compaction rate determination, the free end of biotinylated $\lambda$ DNA was ligated to a short digoxygenin-modified oligonucleotide (oTG227). After tethering, free oligonucleotide was removed from the flow cell by extensive washing, and $\lambda$ DNA free ends were labeled by flowing in anti-digoxygenin QDs. Protein sliding was observed at a labeled protein concentration of $\sim 0.2 \mathrm{nM}$ in $20 \mathrm{mM}$ Tris $(\mathrm{pH}$ 7.5), $100 \mathrm{mM} \mathrm{NaCl}$, and $100 \mu \mathrm{g} / \mathrm{mL}$ BSA.

\section{General bacterial methods}

All B. subtilis strains were derived from the prototrophic strain PY79 (Youngman et al. 1983). Unless otherwise indicated,

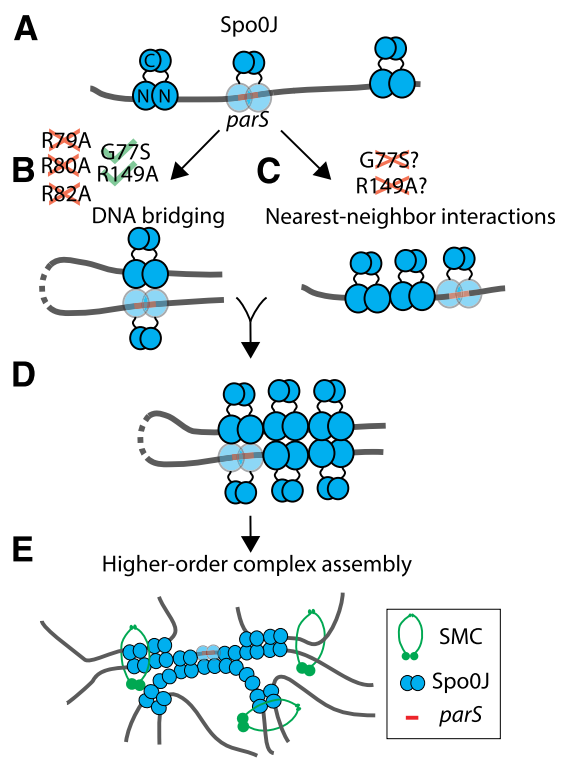

Figure 7. Model of Spo0J nucleoprotein complex formation. $(A)$ Spo0J dimers bind strongly to parS sites and more weakly to nonspecific DNA. The N-terminal DNA-binding domain $(\mathrm{N})$ and C-terminal dimerization binding domain $(\mathrm{C})$ are shown as circles. DNA bridging by SpoOJ $(B)$ traps DNA loops and could cooperate with nearest-neighbor interactions $(C)$ to form larger higher-order complexes $(D)$. $(E)$ The resulting cluster of loops could serve as a platform for SMC loading. For clarity, C-terminal domains are not shown in $E$. The DNA-bridging activity represented in $B$ is what drove compaction of nonspecific DNA in our single-molecule experiments. The R79A, R80A, and R82A mutants are impaired in DNA bridging (shown in $B$ ), which explains why they fail to form complexes in cells. The fact that G77S and R149A mutants are not impaired in DNA bridging implies that they must be impaired in some other way; for instance, in nearest-neighbor interactions $(C)$. 
cells were grown in $\mathrm{CH}$ medium at $37^{\circ} \mathrm{C}$. Tables of strains, plasmids, and oligonucleotide primers and a description of strain and plasmid construction can be found in the Supplemental Material.

\section{Fluorescence microscopy of bacterial cells}

Fluorescence microscopy was performed on a Nikon Ti microscope equipped with a Plan Apo $100 \times / 1.4$ NA phase contrast oil objective and a CoolSnapHQ ${ }^{2}$ cooled CCD camera. DNA was stained with DAPI (Molecular Probes) at $2 \mu \mathrm{g} / \mathrm{mL}$. Cells were immobilized using $2 \%$ agarose pads containing growth medium. Images were cropped and adjusted using MetaMorph software (Molecular Devices). The final figure preparation was performed in Adobe Illustrator.

\section{Acknowledgments}

We thank members of the Loparo and Rudner laboratories, Ned Wingreen, and Chase Broedersz for stimulating discussions. We thank Alan Grossman for anti-SpoOJ antibodies, Matt Waldor for V. cholerae ParB1 protein, Tom Bernhardt and Dirk Landgraf for plasmids, and Bryan Davies for technical advice. Support for this work comes from the National Science Foundation CAREER Award MCB-1148818 (to J.J.L.) and National Institute of Health grants GM086466 and GM073831 (to D.Z.R.). X.W. was a longterm fellow of the Human Frontier Science Program. T.G.W.G. was a recipient of the National Science Foundation Graduate Research Fellowship. D.S. was supported by the Molecular Biophysics Training Grant, Harvard University, National Institutes of Health NIGMS 5T32 GM008313. T.G.W.G. and D.S. purified proteins and performed single-molecule experiments. T.G.W.G. also performed EMSA experiments. X.W. performed in vivo imaging and analysis, immunoblots, and ChIP-seq experiments. C.M.E. performed initial single-molecule experiments. A.M.v.O., D.Z.R., and J.J.L. supervised the project and contributed to the design of experiments. T.G.W.G. assembled the manuscript, X.W. and D.S. contributed text and figures to the manuscript, and D.Z.R. and J.J.L. edited the manuscript.

\section{References}

Autret S, Nair R, Errington J. 2001. Genetic analysis of the chromosome segregation protein SpoOJ of Bacillus subtilis: evidence for separate domains involved in DNA binding and interactions with Soj protein. Mol Microbiol 41: 743-755.

Bartosik AA, Mierzejewska J, Thomas CM, Jagura-Burdzy G. 2009. ParB deficiency in Pseudomonas aeruginosa destabilizes the partner protein ParA and affects a variety of physiological parameters. Microbiology 155: 1080-1092.

Becker NA, Kahn JD, Maher LJ. 2007. Effects of nucleoid proteins on DNA repression loop formation in Escherichia coli. Nucleic Acids Res 35: 3988-4000.

Bingle LEH, Macartney DP, Fantozzi A, Manzoor SE, Thomas CM. 2005. Flexibility in repression and cooperativity by KorB of broad host range IncP-1 plasmid RK2. I Mol Biol 349: 302-316.

Blumberg S, Tkachenko AV, Meiners J-C. 2005. Disruption of protein-mediated DNA looping by tension in the substrate DNA. Biophys J 88: 1692-1701.

Breier AM, Grossman AD. 2007. Whole-genome analysis of the chromosome partitioning and sporulation protein SpoOJ (ParB) reveals spreading and origin-distal sites on the Bacillus subtilis chromosome. Mol Microbiol 64: 703-718.

Broedersz CP, Wang X, Meir Y, Loparo JJ, Rudner DZ, Wingreen NS. 2014. Condensation and localization of the partitioning protein ParB on the bacterial chromosome. Proc Natl Acad Sci (in press).

Chen R, Guttenplan SB, Blair KM, Kearns DB. 2009. Role of the $\sigma^{\mathrm{D}}$-dependent autolysins in Bacillus subtilis population heterogeneity. J Bacteriol 191: 5775-5784.

Chiu C-M, Manzoor SE, Batt SM, Muntaha St, Bingle LEH, Thomas CM. 2008. Distribution of the partitioning protein KorB on the genome of IncP-1 plasmid RK2. Plasmid 59: 163-175.

Dupaigne P, Tonthat NK, Espéli O, Whitfill T, Boccard F, Schumacher MA. 2012. Molecular basis for a protein-mediated DNA-bridging mechanism that functions in condensation of the E. coli chromosome. Mol Cell 48: 560-571.

Edgar R, Chattoraj DK, Yarmolinsky M. 2001. Pairing of P1 plasmid partition sites by ParB. Mol Microbiol 42: 13631370.

Finkelstein IJ, Visnapuu M-L, Greene EC. 2010. Single-molecule imaging reveals mechanisms of protein disruption by a DNA translocase. Nature 468: 983-987.

Garner EC, Campbell CS, Weibel DB, Mullins RD. 2007. Reconstitution of DNA segregation driven by assembly of a prokaryotic actin homolog. Science 315: 1270-1274.

Glaser P, Sharpe ME, Raether B, Perego M, Ohlsen K, Errington J. 1997. Dynamic, mitotic-like behavior of a bacterial protein required for accurate chromosome partitioning. Genes Dev 11: $1160-1168$.

Gruber S, Errington J. 2009. Recruitment of condensin to replication origin regions by $\mathrm{ParB} / \mathrm{SpoOJ}$ promotes chromosome segregation in B. subtilis. Cell 137: 685-696.

Havey JC, Vecchiarelli AG, Funnell BE. 2012. ATP-regulated interactions between P1 ParA, ParB and non-specific DNA that are stabilized by the plasmid partition site, parS. Nucleic Acids Res 40: 801-812.

Hirano T. 2006. At the heart of the chromosome: SMC proteins in action. Nat Rev Mol Cell Biol 7: 311-322.

Ireton K, Gunther NW, Grossman AD. 1994. spo0J is required for normal chromosome segregation as well as the initiation of sporulation in Bacillus subtilis. J Bacteriol 176: 5320-5329.

Kusiak M, Gapczynska A, Plochocka D, Thomas CM, JaguraBurdzy G. 2011. Binding and spreading of ParB on DNA determine its biological function in Pseudomonas aeruginosa. J Bacteriol 193: 3342-3355.

Landgraf D, Okumus B, Chien P, Baker TA, Paulsson J. 2012. Segregation of molecules at cell division reveals native protein localization. Nat Methods 9: 480-482.

Lee PS, Grossman AD. 2006. The chromosome partitioning proteins Soj (ParA) and SpoOJ (ParB) contribute to accurate chromosome partitioning, separation of replicated sister origins, and regulation of replication initiation in Bacillus subtilis. Mol Microbiol 60: 853-869.

Leonard TA, Butler PJG, Löwe J. 2004. Structural analysis of the chromosome segregation protein Spo0J from Thermus thermophilus. Mol Microbiol 53: 419-432.

Lewis PJ, Errington J. 1997. Direct evidence for active segregation of oriC regions of the Bacillus subtilis chromosome and co-localization with the SpoOJ partitioning protein. Mol Microbiol 25: 945-954.

Lin DC, Levin PA, Grossman AD. 1997. Bipolar localization of a chromosome partition protein in Bacillus subtilis. Proc Nat1 Acad Sci 94: 4721-4726.

Liu Y, Chen H, Kenney LJ, Yan J. 2010. A divalent switch drives H-NS/DNA-binding conformations between stiffening and bridging modes. Genes Dev 24: 339-344.

Livny J, Yamaichi Y, Waldor MK. 2007. Distribution of centromere-like parS sites in bacteria: insights from comparative genomics. J Bacteriol 189: 8693-8703. 
Graham et al.

Lynch AS, Wang JC. 1995. SopB protein-mediated silencing of genes linked to the sopC locus of Escherichia coli F plasmid. Proc Natl Acad Sci 92: 1896-1900.

Minnen A, Attaiech L, Thon M, Gruber S, Veening J-W. 2011. SMC is recruited to oriC by ParB and promotes chromosome segregation in Streptococcus pneumoniae. Mol Microbiol 81: 676-688.

Mohl DA, Easter J, Gober JW. 2001. The chromosome partitioning protein, ParB, is required for cytokinesis in Caulobacter crescentus. Mol Microbiol 42: 741-755.

Murray H, Ferreira H, Errington J. 2006. The bacterial chromosome segregation protein Spo0J spreads along DNA from parS nucleation sites. Mol Microbiol 61: 1352-1361.

Rodionov O, Lobocka M, Yarmolinsky M. 1999. Silencing of genes flanking the P1 plasmid centromere. Science 283: 546-549.

Sankararaman S, Marko JF. 2005. Formation of loops in DNA under tension. Phys Rev E Stat Nonlin Soft Matter Phys 71: 021911.

Scholefield G, Whiting R, Errington J, Murray H. 2011. Spo0J regulates the oligomeric state of Soj to trigger its switch from an activator to an inhibitor of DNA replication initiation. Mol Microbiol 79: 1089-1100.

Shebelut CW, Guberman JM, van Teeffelen S, Yakhnina AA, Gitai Z. 2010. Caulobacter chromosome segregation is an ordered multistep process. Proc Natl Acad Sci 107: 1419414198.

Skoko D, Yan J, Johnson RC, Marko JF. 2005. Low-force DNA condensation and discontinuous high-force decondensation reveal a loop-stabilizing function of the protein Fis. Phys Rev Lett 95: 208101.

Skoko D, Li M, Huang Y, Mizuuchi M, Cai M, Bradley CM, Pease PJ, Xiao B, Marko JF, Craigie R, et al. 2009. Barrier-toautointegration factor (BAF) condenses DNA by looping. Proc Natl Acad Sci 106: 16610-16615.

Sullivan NL, Marquis KA, Rudner DZ. 2009. Recruitment of SMC by ParB-parS organizes the origin region and promotes efficient chromosome segregation. Cell 137: 697-707.

Surtees JA, Funnell BE. 2003. Plasmid and chromosome traffic control: how ParA and ParB drive partition. Curr Top Dev Biol 56: 145-180.

Swinger KK, Rice PA. 2004. IHF and HU: flexible architects of bent DNA. Curr Opin Struct Biol 14: 28-35.

van Noort J, Verbrugge S, Goosen N, Dekker C, Dame RT. 2004. Dual architectural roles of HU: formation of flexible hinges and rigid filaments. Proc Natl Acad Sci 101: 6969-6974.

Vecchiarelli AG, Mizuuchi K, Funnell BE. 2012. Surfing biological surfaces: exploiting the nucleoid for partition and transport in bacteria. Mol Microbiol 86: 513-523.

Wagner C, Olbrich C, Brutzer H, Salomo M, Kleinekathöfer U, Keyser UF, Kremer F. 2011. DNA condensation by TmHU studied by optical tweezers, AFM and molecular dynamics simulations. J Biol Phys 37: 117-131.

Wang W, Li G-W, Chen C, Xie XS, Zhuang X. 2011. Chromosome organization by a nucleoid-associated protein in live bacteria. Science 333: 1445-1449.

Wang X, Montero Llopis P, Rudner DZ. 2013. Organization and segregation of bacterial chromosomes. Nat Rev Genet 14: 191-203.

Wright DJ, King K, Modrich P. 1989. The negative charge of Glu111 is required to activate the cleavage center of EcoRI endonuclease. J Biol Chem 264: 11816-11821.

Xiao B, Johnson RC, Marko JF. 2010. Modulation of HU-DNA interactions by salt concentration and applied force. Nucleic Acids Res 38: 6176-6185.

Xiao B, Zhang H, Johnson RC, Marko JF. 2011. Force-driven unbinding of proteins $\mathrm{HU}$ and Fis from DNA quantified using a thermodynamic Maxwell relation. Nucleic Acids Res 39: 5568-5577.

Youngman PJ, Perkins JB, Losick R. 1983. Genetic transposition and insertional mutagenesis in Bacillus subtilis with Streptococcus faecalis transposon Tn917. Proc Natl Acad Sci 80: 2305-2309. 


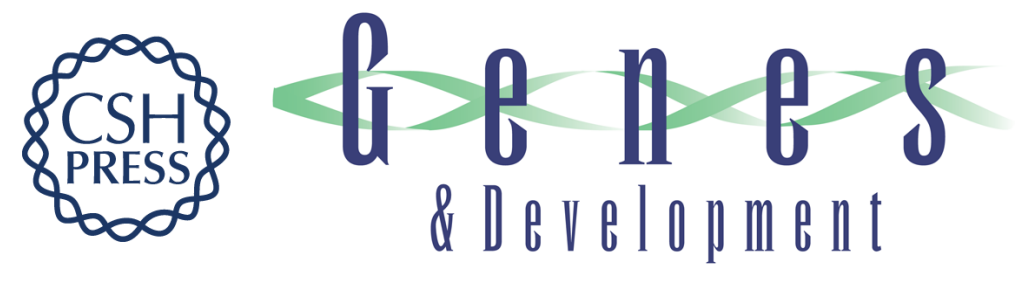

\title{
ParB spreading requires DNA bridging
}

\author{
Thomas G.W. Graham, Xindan Wang, Dan Song, et al.
}

Genes Dev. 2014, 28: originally published online May 14, 2014

Access the most recent version at doi:10.1101/gad.242206.114

\section{Supplemental http://genesdev.cshlp.org/content/suppl/2014/05/09/gad.242206.114.DC1 \\ Material}
Related Content How to build segregation complexes in bacteria: Use bridges
Barbara E. Funnell
Genes Dev. June, 2014 28: 1140-1142

References This article cites 47 articles, 16 of which can be accessed free at: http://genesdev.cshlp.org/content/28/11/1228.full.html\#ref-list-1

Articles cited in: http://genesdev.cshlp.org/content/28/11/1228.full.html\#related-urls

Creative This article is distributed exclusively by Cold Spring Harbor Laboratory Press for the first Commons six months after the full-issue publication date (see

License http://genesdev.cshlp.org/site/misc/terms.xhtml). After six months, it is available under a Creative Commons License (Attribution-NonCommercial 4.0 International), as described at http://creativecommons.org/licenses/by-nc/4.0/.

Email Alerting Receive free email alerts when new articles cite this article - sign up in the box at the top Service right corner of the article or click here.

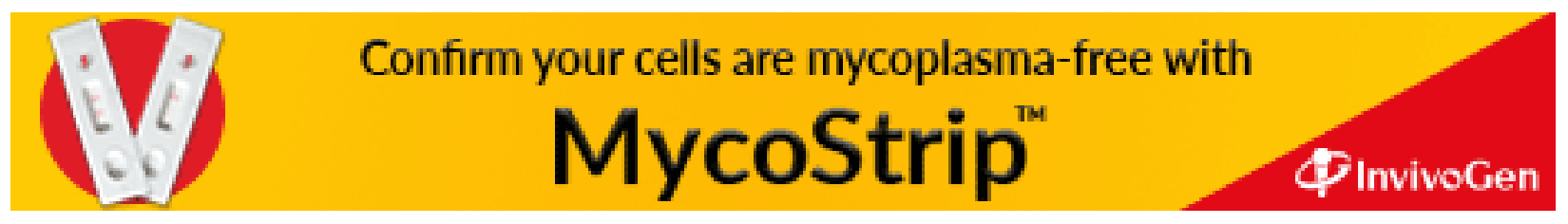

